\section{PELATIHAN PEMBUATAN \\ BAHAN AJAR UNTUK \\ PEMBELAJARAN DARING \\ MENGGUNAKAN \\ APLIKASI VIDEO EDITING BAGI GURU DAN CALON GURU}

Munawaroh', Widya Parimita², Ryna Parlina ${ }^{3}$, Santi Susanti ${ }^{4}$, Ati Sumiati ${ }^{5}$, Sri Zulaihati $^{6}$

1,2,3,4,5,6 Universitas Negeri Jakarta

*Santi Susanti

Email: ssusanti@unj.ac.id

\section{Abstract}

The training is part of the community service activities of the lecturers of the Faculty of Economics, Universitas Negeri Jakarta. This Workshop is to educate and train teachers or prospective teachers to make teaching materials that are certainly interesting for students. Given the current COVID-19 pandemic, where everyone is encouraged to work or distance learning, all teachers must also teach students remotely. In addition, this training is also to prepare teachers to continue to adapt to the times because it is possible that learning and teaching activities will be carried out online and offline in the future.

Keywords: Teaching Materials, Distance Learning, Video Learning

\section{Abstrak}

Pelatihan merupakan bagian dari kegiatan pengabdian masyarakat dari dosen Fakultas Ekonomi Universitas Negeri Jakarta. Workshop dilaksanakan dalam rangka mengedukasi dan juga melatih pengajar ataupun calon pengajar agar bisa membuat bahan ajar yang tentunya menarik bagi siswa. Mengingat saat ini sedang berlangsung pandemi COVID-19 dimana semua orang dihimbau untuk melaksanakan pekerjaan ataupun pembelajaran jarak jauh, maka seluruh pengajar pun harus mengajar para siswa dengan jarak jauh. Disamping itu, pelatihan ini juga untuk mempersiapkan para pengajar untuk bisa terus beradaptasi dengan jaman. Karena tidak menutup kemungkinan bahwa di masa depan kegiatan belajar dan mengajar akan dilaksanakan secara daring dan juga luring.

Kata Kunci: Bahan ajar, Pembelajaran Jarak Jauh, Video Pembelajaran 
Pelatihan Pembuatan Bahan Ajar untuk Pembelajaran Daring menggunakan Aplikasi Video Editing

Munawaroh, Widya Parimita, Ryna Parlina, Santi Susanti, Ati Sumiati, Sri Zulaihati

Volume 1, No. 2, Agustus 2021 hal. 190-194

DOI Artikel : 10.46306/jub.v1i2.35

\section{PENDAHULUAN}

Sejalan dengan Tridarma Perguruan Tinggi yaitu pendidikan, penelitian dan pengabdian pada masyarakat, kami dosen dan mahasiswa Fakultas Ekonomi Universitas Negeri Jakarta melaksanakan Pengabdian Pada Masyarakat berbentuk pelatihan dengan tema "Pembuatan Bahan Ajar Untuk Pembelajaran Daring Menggunakan Aplikasi Video Editing”. Pengabdian Pada Masyarakat dilaksanakan secara rutin setiap tahun oleh dosen Fakultas Ekonomi Universitas Negeri Jakarta.

Pada tahun ini, kami memilih bentuk pelatihan guna mengedukasi dan juga melatih pengajar ataupun calon pengajar agar bisa membuat bahan ajar yang tentunya menarik bagi siswa. Mengingat saat ini sedang berlangsung pandemi COVID-19 dimana semua orang dihimbau untuk melaksanakan pekerjaan ataupun pembelajaran jarak jauh, maka seluruh pengajar pun harus mengajar para siswa dengan jarak jauh. Disamping itu, pelatihan ini juga untuk mempersiapkan para pengajar untuk bisa terus beradaptasi dengan jaman. Karena tidak menutup kemungkinan bahwa di masa depan kegiatan belajar dan mengajar akan dilaksanakan secara daring dan juga luring.

Dalam kegiatan ini, kami tidak hanya memberikan pelatihan namun juga memberikan Challenge atau perlombaan dengan maksud untuk meningkatkan antusias dari para peserta untuk mengikuti acara pelatihan sampai selesai.

\section{METODE PENGABDIAN}

Pengabdian masyarakat ini sebelumnya mengadakan survey terhadap guru-guru yang harus mempersiapkan Pembelajaran Jarak Jauh karena situasi Pandemi Covid-19. Melalui survey tersebut, kegiatan pelatihan menggunakan 7 dasar kebutuhan analisis (Macalister \& Nation, 2020). Berikut gambaran dari metode pelatihan tersebut:

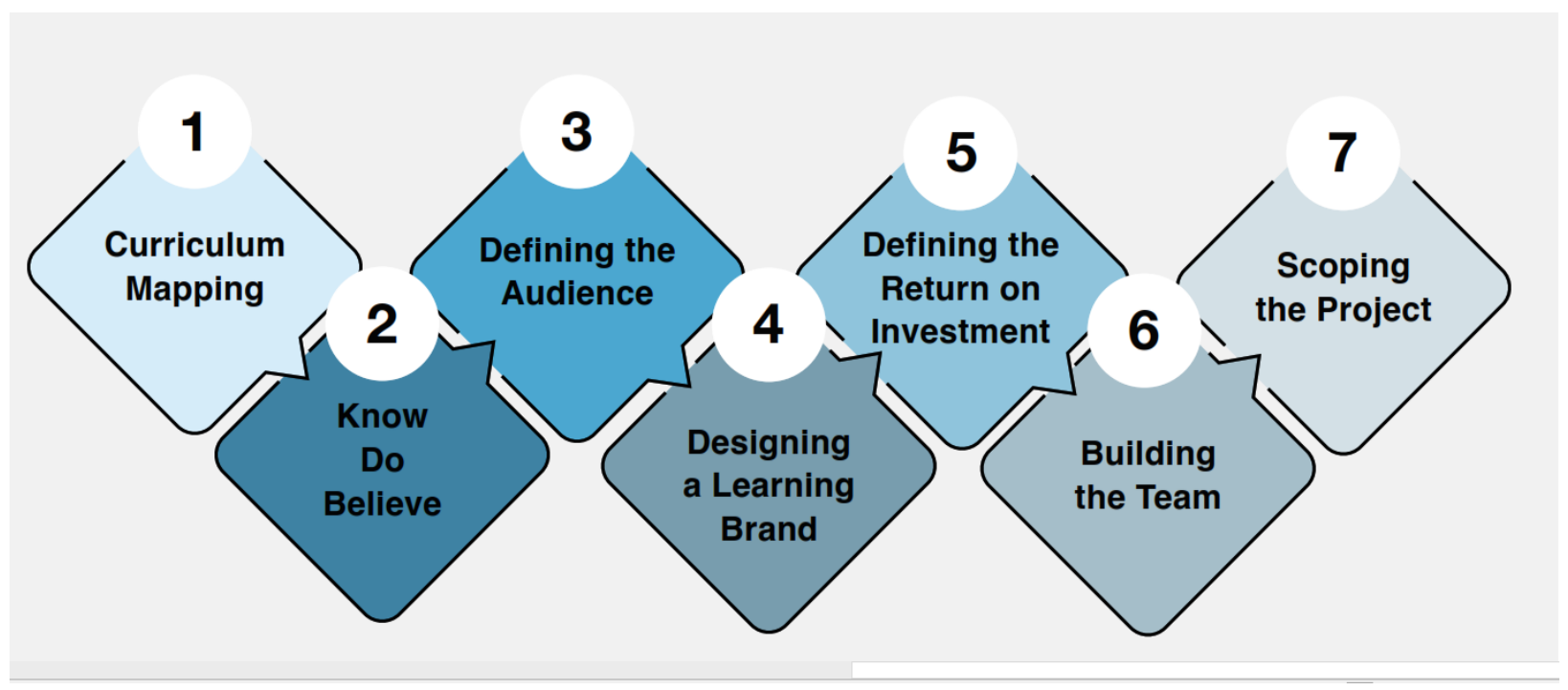

Gambar I. The Seven Essentials of Needs Analysis(Macalister \& Nation, 2020)

Setelah melakukan Analisis kebutuhan guru dalam proses pembelajaran jarak jauh, maka tim menyusun materi pelatihan. Berikut adalah materi yang akan disampaikan pada kegiatan workshop ini.

I. Pembelajaran Daring yang Efektif.

Dalam materi ini dibahas materi diantaranya: Dampak teknologi terhadap proses Belajar Mengajar(Tanwir, Rahman F, \& Rahman F, 2018)(Lestari, 2018) : Manfaat Teknologi bagi guru ("Pemanfaatan Teknologi Informasi dan Komunikasi Bagi Tenaga Pendidik - Direktorat SMP," n.d.) Bagaimana Teknologi membantu siswa(Pada et al., 202I); Mempersiapkan Bahan Ajar ("Makalah : LangkahLangkah Pokok Pembuatan Bahan Ajar," n.d.) 
Pelatihan Pembuatan Bahan Ajar untuk Pembelajaran Daring menggunakan Aplikasi Video Editing

Munawaroh, Widya Parimita, Ryna Parlina, Santi Susanti, Ati Sumiati, Sri Zulaihati

Volume 1, No. 2, Agustus 2021 hal. 190-194

DOI Artikel : 10.46306/jub.v1i2.35

2. Pelatihan Pembuatan Media Ajar dengan Menggunakan Kinemaster(Nubatonis, 202I).

\section{PELAKSANAAN DAN PEMBAHASAN}

Kegiatan Pelaksanaan Pengabdian Masyarakat ini dimulai dengan Pemilihan panitia oleh ketua panitia dimulai pada bulan Februari 202I. Setelah pemilihan tim panitia, kegiatan selanjutnya adalah rapat untuk menentukan tema dan konsep dari kegiatan Pengabdian Pada Masyarakat tahun ini maka didapatkanlah bentuk kegiatan pelatihan dengan tema "Pembuatan Bahan Ajar Untuk Pembelajaran Daring Menggunakan Aplikasi Video Editing” dan juga Video Challenge sebagai implementasi ilmu yang peserta dapatkan. Selanjutnya setiap anggota diberikan jobdesc untuk melaksanakan teknis pelaksanaan dari seluruh rangkaian acara. Hasil rapat dan juga progress setiap anggota dilaporkan kepada ketua panitia secara berkala setiap 2 hari. Berikut adalah poster kegiatan:

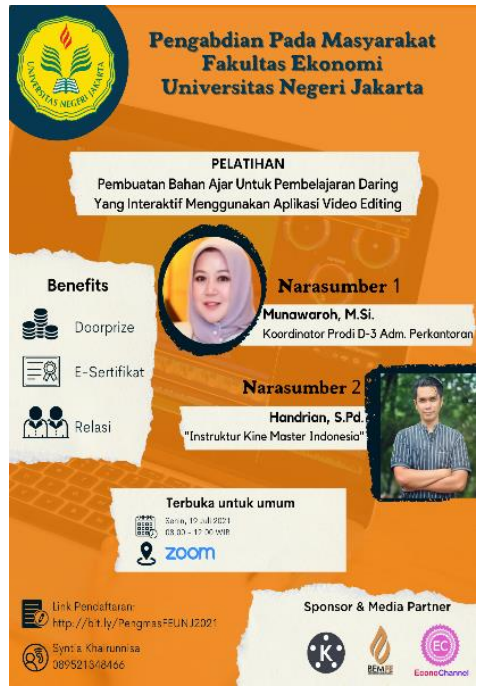

Gambar 2: Poster Kegiatan P2M

Acara Pengabdian Pada Masyarakat ini kami awali dengan Pelatihan yang dilaksanakan pada Senin, 19 Juli 202 I tepat pada pukul 08.00. Pelatihan ini diisi oleh 2 narasumber yaitu Ibu Munawaroh yang juga merupakan ketua panitia dalam acara P2M ini.

Materi yang disampaikan adalah sebagai berikut:

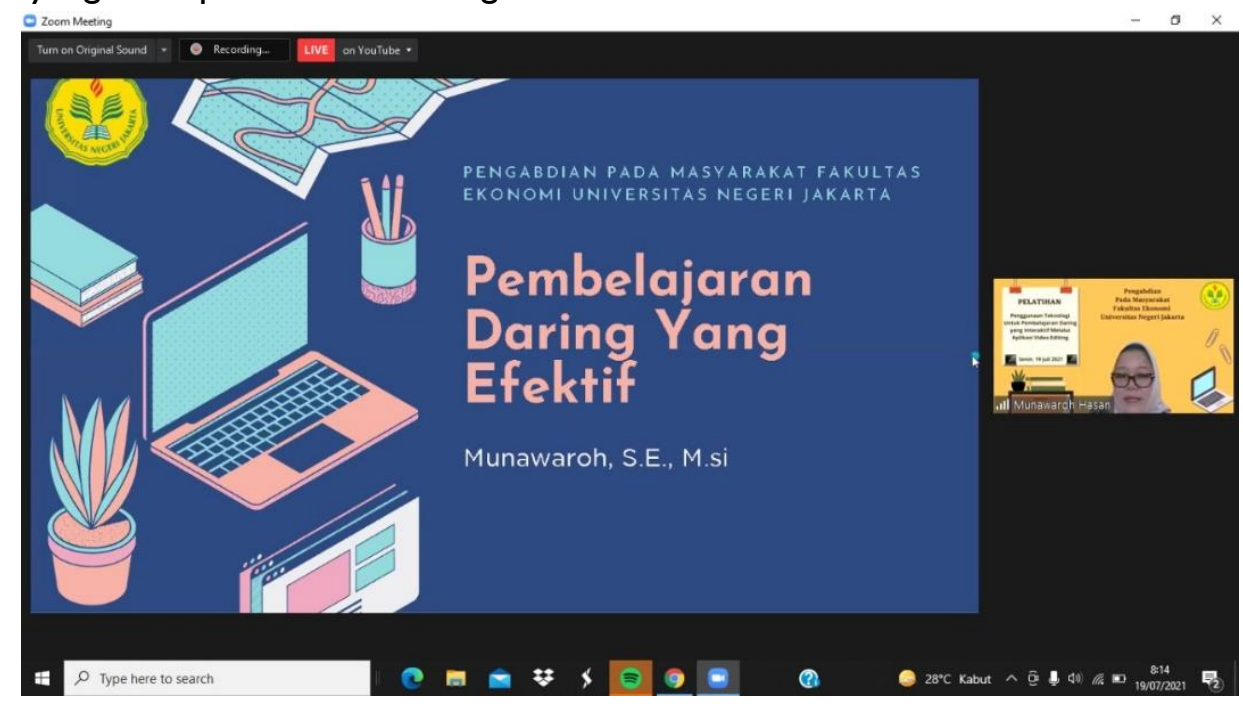

Gambar 3: Materi Pembicara I 
Pelatihan Pembuatan Bahan Ajar untuk Pembelajaran Daring menggunakan Aplikasi Video Editing

Munawaroh, Widya Parimita, Ryna Parlina, Santi Susanti, Ati Sumiati, Sri Zulaihati

Volume 1, No. 2, Agustus 2021 hal. 190-194

DOI Artikel : 10.46306/jub.v1i2.35

Narasumber yang ke dua yakni Bapak Handrian yang merupakan instruktur KineMaster Indonesia. Berikut materi yang diberikan oleh Bapak Handrian:

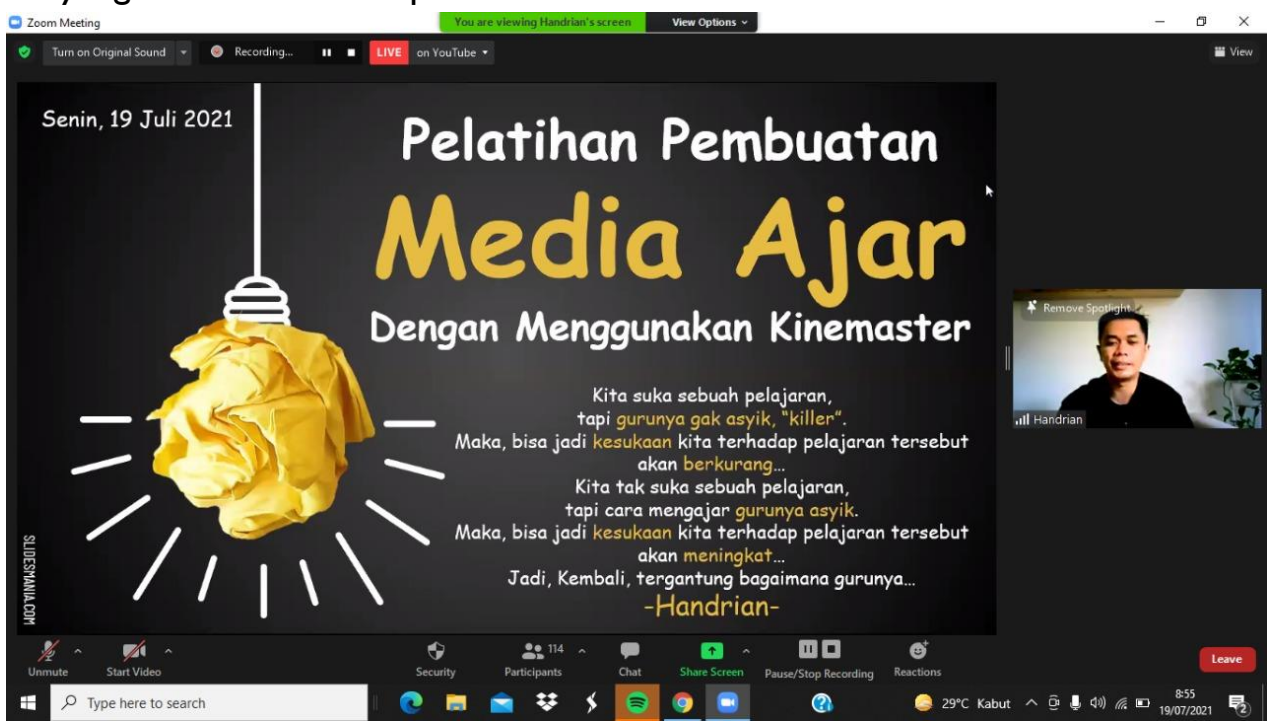

Gambar 4: Materi Pembicara 2

Acara pelatihan ini diikuti oleh lebih 188 peserta dari berbagai kota di Indonesia. Berikut Peserta yang ikut:

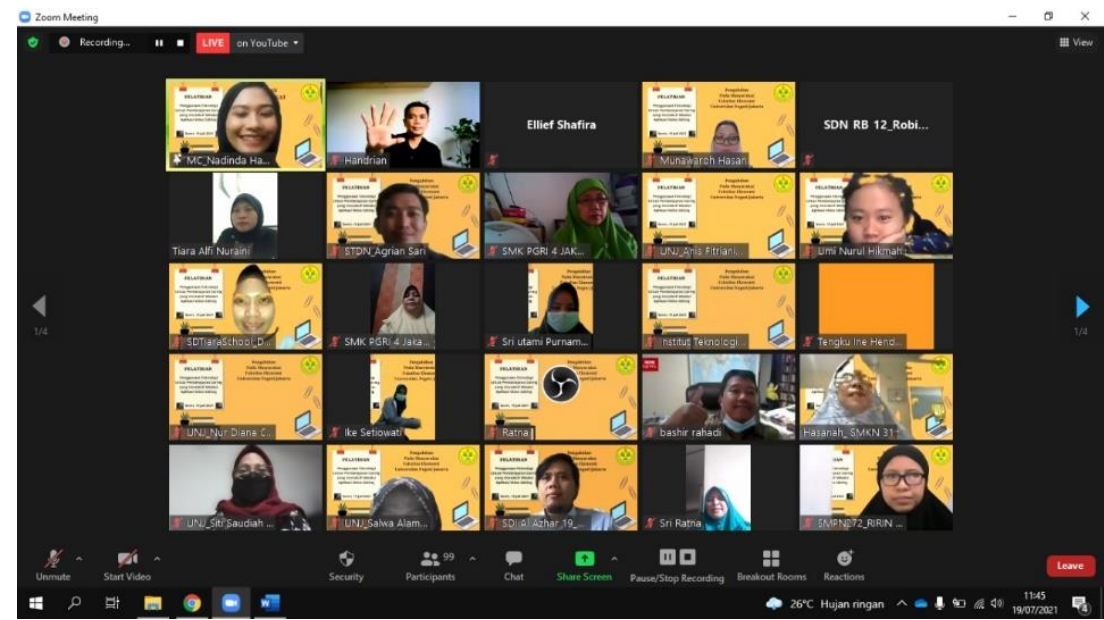

Gambar 5: Peserta Pelatihan

Secara keseluruhan Kegiatan Pelatihan dapat dilihat pada link youtube berikut: https://www.youtube.com/watch?v= b0sWfx6gol\&t=Is

Selanjutnya kami mengadakan video challenge yang mana perlombaan ini merupakan implementasi ilmu yang telah peserta dapatkan pada pelatihan yang sebelumnya diadakan. Perlombaan ini kami adakan tepat setelah acara pelatihan selesai yakni pada Senin, 19 Juli 2021 pukul 12.00 - 23.59. waktu tersebut merupakan waktu pengumpulan karya (Video Bahan Ajar) yang telah peserta buat menggunakan teknik yang diajarkan pada pelatihan sebelumnya. Pengumuman pemenang kami laksanakan melalui media sosial instagram.

\section{KESIMPULAN DAN SARAN}

Kegiatan Pengabdian Masyarakat ini dapat menambah wawasan mengenai tips-tips saat mengajar secara daring, menambah wawasan dan pengetahuan mengenai fitur yang ada pada aplikasi KineMaster, 
Pelatihan Pembuatan Bahan Ajar untuk Pembelajaran Daring menggunakan Aplikasi Video Editing

Munawaroh, Widya Parimita, Ryna Parlina, Santi Susanti, Ati Sumiati, Sri Zulaihati

Volume 1, No. 2, Agustus 2021 hal. 190-194

DOI Artikel : 10.46306/jub.v1i2.35

menambah skill yang dimiliki dalam penggunaan video editing, menambah kreativitas dalam pembuatan bahan ajar dan menambah networking antar guru di Indonesia.

\section{UCAPAN TERIMA KASIH}

Kegiatan Pengabdian Masyarakat ini dapat terselenggara atas Hibah Pendanaan BLU Fakultas Ekonomi Universitas Negeri Jakarta, serta peran partisipatif dari mahasiswa FE UNJ yaitu Syntia Khairunnisa, Ellief Shafira Harfiani, Ardila Sekar Kinanti. Ucapan terima kasih kami haturkan untuk kerjasama dan partisipasinya.

\section{DAFTAR PUSTAKA}

Lestari, S. (2018). Peran Teknologi dalam Pendidikan di Era Globalisasi. Edureligia; Jurnal Pendidikan Agama Islam, 2(2), 94-100. https://doi.org//0.33650/edureligia.v2i2.459

Macalister, J., \& Nation, I. S. P. (2020). Needs Analysis. Language Curriculum Design, 29-43. https://doi.org// 0.4324/9780429203763-3

Makalah: Langkah-Langkah Pokok Pembuatan Bahan Ajar. (n.d.). Retrieved September I6, 202I, from http://rheeviie.blogspot.com/20 I// 0/langkah-langkah-pokok-pembuatan-bahan_23.html

Nubatonis, O. E. (202I). Pelatihan Pembuatan Video Pembelajaran Dengan Aplikasi Bandicam dan Screencast O-Matic. Jurnal Nasional Pengabdian Masyarakat, 2(I), 100-105. https://doi.org// 0.47747/pengabdiankepadamasyarakat.v2il.255

Pemanfaatan Teknologi Informasi dan Komunikasi Bagi Tenaga Pendidik - Direktorat SMP. (n.d.). Retrieved September 16, 202I, from http://ditsmp.kemdikbud.go.id/pemanfaatan-teknologi-informasi-dankomunikasi-bagi-tenaga-pendidik/

Tanwir, T., Rahman F, A., \& Rahman F, A. (2018). Dampak Penggunaan Media Pembelajaran Berbasis Ict Terhadap Hasil Belajar Pai Peserta Didik Pada Smk Negeri I Kota Parepare. AL-ISHLAH: Jurnal Pendidikan Islam, I6(I), I I-36. https://doi.org/I0.35905/alishlah.vI6il.732 